of paper, is apt to lose its purity and acquire.confusing. line and bands of ordinary copper-chloride, by oxidation, which the preparation then undergoes spontaneously, before igniting it For pyrotechnists, therefore, it seems scarcely probable that the subchloride of copper, with its pure cerulean flame, will ever be of any very useful value. But as a parallel example of a coloured-fire composition, it may be mentioned here, that powdered Val-Traversite (a bituminous limestone found near Neuchatel, in Switzerland), on account of its prodigious natural richness in bitumen, when mixed with sufficient chlorate of potash, also burns self-supportingly, with a fine orange-red flame in which the familiar spectrum of calcic oxide is, of course, most vivid. Were hot asphalt, pitch, or bitumen, instead of hot glycerine, used to dissolve or to "masticate" the dry subchloride of copper when it is freshly made, a copper-chlorinated mass would be produced which would probably be capable of resisting atmospheric action, and whose mixture with chlorate of potash would, like the similar Val-Traversite mixture, probably also not suffer by keeping and exposure, and would furnish a source of blue flame and of the significantly simple spec rum of subchloride of copper, not less vividly true and fixed in their distinctness, than the orange-red light and strongly pronounced calcic-oxide spectrum of the other combination of chlorate of polash with a bitumen-containing substance.

As regards the blue salt-flame, whose spectrum in its purity shows no conspicuous lines, or hands of greatest brightness, it can hardly be doubted that the element chlorine, from the positions of its own principal line groups, contributes mainly to produce the blue color tion, at a temperature, in the fire, which is not high enough to dissociste the sodic chloride and liberate sodium vapour, with its tell-tale yellow line, from its chemical union. In the green flame of chloride of copper the colouring groups of lines show a more detailed resemblance than this to the chief colorific lines in the elementary chlorine spectrum, while in copper subchloride's "bluest of blue" flames, the wide green light-bands of copper chloride fade out, leaving the colorific light concentrated almost entirely in three close pairs, or in six bright lines, which, if they do not coincide in place with, are at least not far di-tant in position from, three chief

I A very suggestive example of a substance's detection by recignition of its spectrum was described, with a drawing of the recurded spectra, by Mr. its spectrum was described, with a drawing of the recurded spectra, by Mr. A. Percy Sinith, in a short notice of a series if observations on the spectra
of chlorides, and on the blue fla ue if comm in salt. in the C/emical News, of chlorides, and on the blue fla ue if comm in salt. in the Chemical Nezs, vol. 39, p. ${ }^{4}$ : (1879). An examination of the flame-spectra of several similarity among thein al to the spark. Or flame-spectrum of hydrochloric similarity aming them al to the spark. or flame-spectrum of hydrochloric
acid gas. This gas showed a belt of green lire-ban fs which azreed in their acid gas. This gas showed a belt of green lire-ban ts which azreed in their main positions with the green portion of a long array of band-pair shown with much constancy by several differen alka ine and earthy chlorides, and
especially by ammoninm chlo ide, and hy mercurous chloride for calomel, where the agreement wan also verified by a direct comparison), in a Bunsen fame: but no lin:-counterpar s to the equally bright, blue-lined portion of the same constant spectral striation were observable in the hydrochl ric acid spectrum.

From the easy conversion of ch'orides into the corresponding oxides in a air-gas flame, when the flam: is not kept artific ally saturated with hydrochloric acid gas, we might pret y certainly assume that in the flame's ordinary condition, the heated chl rides would always diseng age sufficien chlorine to produce by comb na ion with hydr gen in the coal-gas of the flame, traces of the stable product, hudrochloric acid gas, among the ga.es of the flame's combustiun; and the different chlorides would thus, by suppositions which may not perhaps be unlike $y$ an $f$ ina tmissib'e, all supply the flame alike with the ubstanial faciur needed, for the appearance of the greeli line portion of the constant spe trum.

At the same time new carbor - compoland: $w$ uld be formed by dehydration of the flame's gaseous hydrocarbons, to furninh hydrogen to the liberated chlorine, and some constant carb. n-gases then. of not yet known descriptions, might be conjectured just as comprehenstbly and filly, to be c n. tions, might be conjectured just as comprehenstyly and filly, to be c n
currently prodtctive in the cons an t chloride.rank's illumination, of the blue. line portion of its bands, if which no spectal counterparts could be detected in the hydrochloric acid si ectrum.

But whether the inteses ing figure and deccr.ption given by Mr. A. Percy Suth in the ab, ve pap-s, of his long series of experiment, may or may not Smith in the ab, ve pap-r, of hi $>$ long series of experiment-, may or may not
admit of such a simple spectro chem cal int rpreation. the conflicts of conadmit of such a simple spectro chem cal int rpreation. the conflicts cif conchl ric acid in flames fed with different chlorides turnishes such a wonderful example, give weight and value to the notes of the discovery recorded by Mr. A. Percy $S$ uth, in a new wide field f the spectroscope's utility, which are of much deeperinteres than any ingle theory to account only for th.s particular recognition and discovery itself.

Mr. A. Percy Smith's own cxpitally base1. and clearly proved deductionfrom his numerous experineits, were acco-dingly. in prospect of their further prosecution, expressed thus, quite generaly:-that the blue fiame of common salt in a hot tire owe; its col ritio, to reaction: either exactly or very nearly simlar to those which produce resemblance of a nearly cunstan spectral type in different chloride flames. to that of hydrochloric acid: and that, agan, among the partly undetermined. an 1 perhaps to some exten variable reacti ns which pr iduce tne imilarty, there appear to be so ne which disturb and molify th: ordinay amp :arancs of th: hydrochlorio acid spectrum, and which would appear $t$, suptrads to it a series of blue line-bands which, as it is presented in a $\mathrm{f} / \mathrm{m}$, or electrically in vacuum tuhes, the spectrum of pure hydrochl ine acid gits alone doss not usually
exhibit. line-pairs in the ordinary spectrum of chloride of copper. There is much in these resemblances which betokens some kind of continuity of connection with the primary features of the chlorine spectrum itself; the evidences of which; although thus displayerl by cop er and chlorine in the spectroscope, may perhaps be sensibly regarded as having some near relation of analogy to the appearance of variable chemical combining power under the influence of light, between silver and chlorine, presented in photography. But there is also, undoubtedly, a very marked distinction between the "spectroscopic reactions" of these two different copper chlorides; and, similarly, there are in the apparently mutable photochemical affinity between silver and chlorine in photography, two fairly stable delimitations of its range, in the "subchloride" (or as it has been termed by $\mathrm{Mr}$. Clement Lea, the "photochloride") of silver, and in ordinary silver-chloride. Further discriminations of the copper-chloride spectra in intermediate forms which they seem to comprise transitionally between the two definite ones of the chloride and subchloride, would perhaps extend and strensthen this analogy, and may not impossibly help, at some future time, to explain and illustrate it, if there is any real soundness in it, more fully and completely.

The example of fluoride of calcium is a curious one in spectrum analysis, where sprinkling fluor-spar dust in a Bunien-flame produces, in addition to the normal calcic oxide spectrum of one orange-red and one green band, a second bright and narrow green one at a distance from the first about equal to that of the red band from it. There are no. other distinguishable bands. But if the pair of normal ones is really due to calcium-oxide vapour produced by decomposition in the flame, it is not very easy to conjecture to what other product of decomposition the additional, sharply defined and brilliant, solitary green band can be ascribed. The spectrum of hydrofuosilicic acid gas presents a very gorgeous band-array of violet-blue lines, whose lustrons group is prubably indicative of near neighbourhood in place to some bright line concentration in the spec rum of fluorine itself; but if so, the collection of its colorific strength in the single additional green line of the fluor-spar spectrum, seems to imply a freedom from. uniformity in fluorine's power of imparting spectral coloration to its crmpounds, just opposite to the sensible continuity and kinship of spectral clusterings, above described, which the presence of chlorine appears to inpose upon its compounds by common resemblances discernible in the blue lightascendencies of the fire-flames of common salt, chloride and subchloride of copper, when they are spectroscopically analyzed.

Observatory House, Slough, March 3.

A. S. HERSCHEL.

\section{Brush-Turkeys on the Smaller Islands North of Celebes.}

THE reviewer of Dr. Hickson's book, "A Naturalist in North Celebes" (March 20, p. 458), believes that the brush-turkey or moleo, Megacephalon wateo, has never been recorded as occurring in the smaller islands north of Celebes. I bey to remark that in the year 1879 I recorded this species from-Siao, and in the year I 884 from Great Sangi, on both of which islands, besides, occurs a Megapodizs peculial to them, viz. $M$, sanghirensis, Schlegel, representing there $M$, gilberti, Gray, from Celebes (see the Ibis, 1879, p. 139; Isis, 1884, pp. 6 and 53 , \&c.). Perhaps Mr. Gullemard did not $\mathrm{c}$ mprise Siao and Great Sangi under the head of "smaller islands" " but Dr. Hickson himself (p. 95) records two brush-turkeys from the smaller island of Tagulandang, a larger and a smaller one, and these must be Negacephalon maleo and a Megapolizus. Tagulandang is situated between Celebes and Siao, and much nearer to the latter island. From the volcano islet of Ruang, opposite and withm about a: mile from Tagulandang, he only records (p. 4I) one brush-turkey, and this, of course, may be either the Megacephalon or a Megapodizes, if both do not occur, as appears rather probable. When 1 visited Ruang in $187 \mathrm{I}$ after the heavy eruption in March of that year (see NATURE, vol. iv. p. 286), nearly the whole of its forest was destroyed and burnt down, and $I$ do not believe that a living brush-turkey then remained on the islet; but it has since been repeopled from its near neighbour, Tagulandang, where both species occur, and therefore, if the one could reach Ruang, the other may have reached it too. This is of no consequence at all. Dr. Hickson's following remark as to brush-turiseys on Tagulandang (p. 95), "The larger bird is perhaps the Merafodius sanghireztsis of Schlegel, a brush turkey, which is bugger than the Negacephalon, and extends over the Sangir Islands," contains a mistake, as $M$. sanghirensis is much smaller than 
Meoacephalon mileo. The reviewer corrects, by the way, my calling the Celebean whimbrel Numenius phoopus, saying that it is probably $\boldsymbol{N}$. wroprgialis, but these two names are synonymical, cf. for instance, Salvadori, Orn. Pap., iii., 332, 1892, sub $N$. variegatus. As to its nesting on small trees "small brushes" were intended to be implied (see Legge, "Birds of Ceylon," I880, p. 913).

Royal Zoological Museum, Dresden, March 22.

\section{Crystals of Lime.}

IT was pointed out to me by Mr. W. J. Pope, of the City and Guilds of London Institute, that a lime cylinder which had been used in the Jantern during a lecture had become distinctly crystalline where affected by the oxyhydrogen flame.

Examined under the microscope by polarized light, the crystals are seen to be well-defined cubes with striated faces. When immersed in water they break up and give rise 10 minute doubly refracting plates of rhombic outline, behaving in this respect like ordinary lime; the cubic crystals, however, are less rapidly affected by exposure either to air or water than is amorphous lime.

Lime is commoniy stated to be infusible at the temperature of the oxyhydrogen blow-pipe; and the only crystals previously recorded, so far as I know, are those obtained by Brigelmann, by fusing calcium nitra'e (Annalen der Ploysik und Chemie, ii. p. 466 , iv. p. $277,1877-78$ ). It seems, therefore, worthy of notice that they are possibly al ways formed upon the surface of the lime cylinders by the action of the oxyhydrosen flame.

The crystals resemble in all respects those described by Brigelmann. The jet used on the present occasion was an ordinary blow-through jet.

H. A. Miers.

Foreign Substances attached to Crabs.

I AM giad to see that Mr. Garstang agrees with me in regarding the presence of the Ascidians on Hyas as accidental.

I. had no intention of decrying the value of Mr. Garstang's experiments with Ascidians, but his rule might, perhaps, be limited to those memhers of the group to which it can be proved to apply. Under natural conditions it apparentlv fails to apply to $P$. corrugata and $M$. arenosa. As to the latter, Prof. McInto-h assures me that he has freyuently found it in the stomach of the cod and haddock.

The appreciation of the cod for $A$. mesembryanthemum is, I think, sufficiently proved by the fact that the latter is one of the most successful cod-bait; used here.

St. Andrews Marine Laboratory, March 29.

ERnest W. L. Holt.

Wimshurst Machine and Hertz's Vibrator.

IT may interest those who wish to repeat Hertz's experiments on electro-magnetic radiation to know that many of these can be lone very well by using a small Wimshurst machine in place of the usual induction coil and battery. The vibrator and resonator which we used were like those described in NATURE (vol. xxxix. p. 548), and the Wimshurst machine had two I 2 -inch plates (giving at most with the jars on a 4 -inch spark). The wires from the vibrator, instead of being connected with an induction coil, were connected with the two ouler coatings of the jars of the machine. The machine spark-gap and the vibrator spark-gap should be so adjusted that when a spark occurs at the former one also occurs at the latter. With the apparatus described we got good results when the spark-gaps were $38 \mathrm{~mm}$. and $3 \mathrm{~mm}$. respectively. The outer coatings of the jars are only connected together by the wood of the machine, but it is some times an advantage to put a few inches of damp string between the balls of the vibrator.

This combination, is obviously a modification, adapted to work a Hertz vihrator, of one of Dr. Lodge's well-known Leyden jar arrangements.

No doubt many persons have connected the vibrator directly with the terminals of the machine, but this arrangement does not work nearly so well.

T. A. GarretT. W. LUCAS.

THE INSTITUTION OF NAVAL ARCHITECTS $\mathrm{THE}$ annual meeting of the Institution of Naval $\mathrm{Ar}$ 1 chitects was beld under the presidency of Lord Ravensworth, on Wednesday, Thursday, and Friday of last week. There was a fair list of papers on the programme, although at one time, shortly before the meeting. it was jeared that there would be a sad lack of contributions from members. At the last ninute, however, one or two papers came in, and the list, although perhaps below the average in the importance of the memoirs. was of passable interest.

The following is a consecutive enumeration of the business that was transacted at the meeting:-

Wednesday, March 26th: morning sitting-Annual Report of the Council, an 1 other routine business ; Address by the President. Paper read and discussed-Notes on the recent naval manceuvres, by Mr. W. H. White, F.R.S., Director of Naval Construction

Thursday, March 27th: morning sitting-The Maritime Conference, by Rear-Admiral P. H. Colomb; strength of ships, with special reference to distribution of shearing stress over transverse section, by Prof. P. Jenkins; steatite as a pigment for anti-corrosive paints, by $\mathrm{Mr}$. F. C. Goodall. Evening sitting-On the evaporative efficiency of boilers, by Mr. C. F. Stromeyer; on the application of a system of combined steam and hydraulic machinery to the loading, discharging, and steering of steam-ships, by Mr. A. B. Brown; the revolving engine applied on ship-board, by Mr. Arthur Rigg.

Friday, March 28th : morning sitting-On leak stopping in steel ships, by Captain C. C. Penrose Fitzgerald, R.N. on the variation of stresses on vessels at sea due to wave motion, by Mr. T. C. Read; spontaneous combustion in c.sal ships, by Prof. Vivian Lewes. Evening sitting-. Experiments with life-boat models, by Mr. J. Corbett ; on the screw propeller, by Mr. James Howden.

The annual dinner was held on the evening of Wednesday.

Out of the above list of a dozen papers there were fewer than usual of scientific interest, ant, indeed, in one or two instances they were not either distinguished by practical interest. Mr. White's paper, which formed the pieco de resistance of the meeting, was of military rather than scientific importance, and was chiefly notable from the number of admirals that took part in the discussion; indeed, the whole naval contingent of the Board of Admiralty was present to hear the paper read. Admiral Colomb's paper on the recent Washington Maritime Conference was practically reduced to a consideration of the rule of the road at sea. The general opinion of the authorities assembled appeared to be that the present rulc of the road is very well as it stands, with the exception that the "holding-on ship" should not be required, or even allowed, to slacken her speed. This seems in conformity with common-sense. If two ships arc converging towards a point, say at right angles to each other, and one shifts her helm to go under the other's stern, if the second, or holding-on ship, slacken speed, the probability will be that the giving-way ship will crash into the other's broadside or cross hel bows; in the latter case, there is probability that the holding-on ship will give the other her stem. What is most wanted when danger of collision arises, is certainty on each vessel as to what the olhar may be going to do. If the holding-on ship never slacken speed-is not allowed to slacken speed-then the other vessel knows exactly what course to take; as the law stands, the quartermaster, or officer in charge, is never quite sure until the last minute, e-pecially at night, whether the other ship considers there is danger of collision or not, and, therefore, whether she will slacken or keep to full speed. We anticipate the proposed alteration, if put in force, will greatly lessen the list of collisions.

The memoir contributed by Prof. Jenkins on the strength of ships was decidedly the most important contribution to naval science of this year's meeting. The paper will open up to the majority of those practi- 